\title{
Article
}

\section{Developing, validating and testing a Ward Environment Assessment Tool: WEAT}

Durosaiye, Isaiah Oluremi, Hadjri, Karim, Liyanage, Champika Lasanthi and Chrysikou, Evangelia

Available at http://clok.uclan.ac.uk/31660/

Durosaiye, Isaiah Oluremi, Hadjri, Karim, Liyanage, Champika Lasanthi ORCID: 0000-0001-6687-3611 and Chrysikou, Evangelia (2020) Developing, validating and testing a Ward Environment Assessment Tool: WEAT. Journal of Nursing Management, 28 (3). pp. 548-558. ISSN 0966-0429

It is advisable to refer to the publisher's version if you intend to cite from the work. http://dx.doi.org/10.1111/jonm.12956

For more information about UCLan's research in this area go to http://www.uclan.ac.uk/researchgroups/ and search for <name of research Group>.

For information about Research generally at UCLan please go to http://www.uclan.ac.uk/research/

All outputs in CLoK are protected by Intellectual Property Rights law, including Copyright law. Copyright, IPR and Moral Rights for the works on this site are retained by the individual authors and/or other copyright owners. Terms and conditions for use of this material are defined in the policies page.

\section{CLoK}

Central Lancashire online Knowledge www.clok.uclan.ac.uk

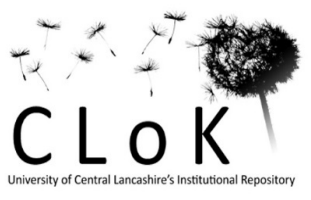




\section{Journal of Nursing Management}

Developing, validating and testing a Ward Environment Assessment Tool: WEAT

\begin{tabular}{|r|l|}
\hline Journal: & Journal of Nursing Management \\
\hline Manuscript ID & JNM-19-0400.R1 \\
\hline Manuscript Type: & Original Article \\
\hline Topic Areas: & $\begin{array}{l}\text { Human Resource Management, Middle Manager, National Health Service } \\
\text { (NHS), Nurse Managers, Nursing Management, Work Environment }\end{array}$ \\
\hline Research Methods: & Case Study, Content Analysis \\
\hline
\end{tabular}

\section{SCHOLARONE ${ }^{\text {m }}$} Manuscripts 


\title{
Developing, validating and testing a Ward Environment Assessment Tool: WEAT
}

\begin{abstract}
Aims

To develop, validate and test a ward environment assessment tool (WEAT) for post-occupancy evaluation of hospital wards from the perspectives of ward nurses, using Person-Environment fit theory.

Background

It is argued that as the needs and expectations of various user groups of healthcare facilities would vary, so would the tools to measure the suitability of the architectural design features of these healing environments for different groups of users. However, a review of relevant literature revealed that there is a dearth of assessment tools to appraise the adequacy of healthcare facilities for nursing staff.

Methods

Extant literature was reviewed to construct WEAT. Twenty ward nurses were interviewed to obtain user perspectives on the ward environment. Post-occupancy evaluation of three hospital wards was undertaken to validate and test WEAT.

Results

WEAT: A new post-occupancy evaluation tool was created.

Conclusions

WEAT measures the impacts of ward environment on nurses in four personal constructs; namely physical, cognitive, sensory and universal.

\section{Implications for Nursing Management}

WEAT is an innovative management decision-making tool for ward managers, who may use its results to argue for workspace redesign with facilities managers, explore job readjustments with occupational health nurses, and review job description with human resource managers.
\end{abstract}

Keywords: Post-occupancy evaluation, Person-Environment fit theory, hospital ward, ward nurse, architectural design features, personal constructs 


\begin{abstract}
Aim
This paper is a summary of the development, validation and testing process of a ward environment assessment tool (WEAT) for the post-occupancy evaluation (POE) of a hospital ward from the perspectives of ward nurses. Additionally, the study explores how architectural design features of hospital wards could be used to create a fit between ward nurses and the ward environment, by applying the PersonEnvironment fit theory (Vischer, 2007).
\end{abstract}

\title{
Background
}

The benefits of good design in healthcare environment are widely acknowledged (Lu and Zimring, 2012, Choudhary et al., 2009). A way to establish how well a hospital environment meets the needs and expectation of its users is by undertaking a POE of the built environment. POE is a "process of evaluating buildings in a systematic and rigorous manner after they have been built and occupied for some time" (Preiser, 2001, p. 9.). However, a major impediment to the widespread use of POE is to determine the parameters of the buildings that should be subjected to evaluation from the perspectives of the users. In addition, even when the parameters of evaluation are determined, a further question is to decide on the most adequate instrument that would measure those parameters reliably. While POE has been widely criticised for its ex post (Durosaiye et al., 2019) nature and there are advocates for 'pre-occupancy evaluation' (van der Zwart and van der Voordt, 2015), the POE still remains the most reliable way of establishing how a built form fulfils the requirements of its users.

While there is a broad recognition of the benefits of undertaking POE, its industry-wide application has, hitherto, been challenged by a number of practical obstacles, including implementation costs; a lack of well-articulated guidance of shared responsibilities among stakeholders; and an exclusion of POE from professional curricula (Hadjri and Crozier, 2009). Some of these challenges have been partly addressed by the Royal Institute of British Architects' most recent overhaul of its Plan of Work, into which POE has been introduced; however, there is still no guidance on specifications relating to complex buildings, such as healthcare facilities (Royal Institute of British Architects, 2013). Despite the available research evidence, POEs are hardly ever conducted on hospital ward environments from the perspectives of the nursing staff. 
Annandale et al. (1999) purport that the most important criteria of a useful measurement tool are that it must be theory-based, reliable, valid, relevant to the unit of analysis, and relatively easy to administer. However, measuring the characteristics of the physical environment in a healthcare setting with respect to how well they meet user needs is quite a daunting exercise. An effective environmental assessment tool should be designed to gauge the actual level of performance of the facility against predetermined standards and/or against user needs and expectations.

\section{Theoretical underpinning}

The development, validation and testing of WEAT is underpinned by the Person-Environment fit theory (P. E fit). The P-E fit theory describes the compatibility or the discord that originates from the interaction between an individual and their environment (Kristof-Brown and Guay, 2011). Historically, P-E fit theory has been used to study a person's behaviour in relation to, or during an interaction with, their environment (Lewin, 1939). Rooted in the field of environmental psychology, the underlying assumption of the P-E fit theory is that behavioural outcomes are a function of the interaction between the person and their environment (Jansen and Kristof-Brown, 2006). A subset of the P-E fit theory proposed by M. Powell Lawton is the 'environmental docility hypothesis', which suggests that an individual's behaviour coming in contact with an environment is relative and the analysis of such a behavioural response cannot be based solely on our knowledge of personal traits or the environmental stimuli, but on the prevailing transactions between the two components in P-E fit (Lawton and Nahemow, 1973). Lawton was one of the pioneers of the study of P-E fit theory and its application to the built environment, especially with respect to housing for older persons (Lawton et al., 1975, Lawton, 1970). Vischer (2007) furthered this thinking and expanded the application of the P-E fit theory to workplace design, claiming that people need to be more than healthy and safe in the buildings they occupy, as environmental comfort emerges as a predominating factor in the workplace.

Underpinned by the P-E fit theory, WEAT can be used to establish how architectural design features of hospital wards could create a fit between ward nurses and the ward environment. Therefore, it is necessary to establish what constitutes the 'Person' and what the 'Environment' depicts in the P-E fit theory in the construction of WEAT. In this context, it is argued that an enabling environment enhances work ability of ward nurses, while a 'disabling' environment poses an impediment to nurses' abilities to carry out their job 
duties. To create a fit between ward nurses and their work environment, this study must devise a way to establish what architectural design features of the hospital wards would be the 'enablers' and which would be potentially the 'disablers'. This thus raises the question of what characteristics of the 'Person' and what attributes of 'Environment' would be subject of empirical investigation in the implementation of WEAT. In the development of WEAT, it was theorised that a functional fit could be attained between ward nurses (P) and the ward environment $(E)$, through the architectural design features of the nursing practice environment. This means that the notion of a 'fit' or 'misfit' in the P-E fit is more than a theoretical conceptualisation.

\section{Definitions}

Certain terms have been used in WEAT, which require specific definitions in the context of this paper. These are explained in this section.

Personal constructs of nurses are the personal traits nurses must employ while encountering the architectural design features of hospital ward elements (Citation removed for blind peer review). The four personal constructs include, physical, cognitive, sensory and universal.

Personal Construct Impact (PCl) Score is the sum of all the architectural design features observed in a ward element, during the POE, expressed as a percentage of the total number of architectural design features for which the ward element was evaluated. The higher the $\mathrm{PCl}$ score of a ward element in a particular personal construct, the better designed it is presumed in supporting that personal construct.

Physical Construct is the physical strength nurses employ in coping with the physical demands associated with their job role (Trinkoff et al., 2003) in the ward environment.

Cognitive Construct is the mental faculty or cognitive resource of nurses that enhances or enables cognitive processes (Salthouse, 1990), and is required of nurses to manage the non-physical workload inherent in the nursing profession.

Sensory Construct relates to the ability of nurses to apply the five senses, including auditory, gustatory, olfactory, sight, and tactile (King, 2012), while performing their duties.

Universal Construct describes the ability of ward nurses to make a choice over, or control their, immediate environment, constituting the ward elements (Lewis et al., 2010).

Architectural design feature (ADF) is a design characteristic of the ward environment that assigns functionality to a ward element and enhances seamless interaction between that ward element (Monroe 
et al., 1997) and its users (Peri Bader, 2015). In this study, ADFs include attributes of the ward environment such as layout, accessibility of spaces, signage, lighting, colours, sound insulation, ventilation, thermal comfort and furnishing (Prochorskaite et al., 2016).

Ward element is the physical space of hospital ward that offers functional support to patient therapeutic healing process and facilitates nursing tasks. The 14 ward elements identified are named as follows: nurse station, patient bay, side room, staff room, ward manager's office, doctor's office, day room, corridor, storage room, clean utility, sluice, bathroom and WC, kitchen and entrances and exits.

\section{Methods}

The methodology followed in this research is the case study approach (Yin, 2009). Robson (1993) sees case study as a research method used to undertake a specific form of enquiry in which a case is captured in its uniqueness and unstructured data is collected about the case. In this study, data collection was undertaken at a National Health Service (NHS) Trust in the UK. While the choice of NHS Trust was convenience, due to its proximity to one of the researchers' institution, the main selection criterion was that the three wards must be inpatient wards with some amount of patient turnover. Participants were recruited from three wards of the Trust and these wards also formed part of the POE undertaken in this research. Data collection was from three different sources, namely, a review of extant literature, interviews with the 20 ward nurses and POE of three NHS hospital wards where the ward nurses worked (Citation removed for blind peer review). The POE was undertaken using the newly constructed WEAT POE checklist. The interviews were transcribed and analysed using NVivo 11 for Windows. The corresponding author's institutional approval was obtained prior to data collection. All participants gave their written informed consent to participate in the study.

Description of the Facilities: Three wards were selected for this POE study. They are labelled Ward A, Ward B and Ward C. All the three wards are located in different buildings of the NHS Trust.

Ward $\mathbf{A}$ is a surgical ward specialised in the upper gastrointestinal treatment of patients. It contains 23 patient beds and three nurse stations. Two of the nurse stations are located on the corridor, while one is situated in one of the patient bays where special care patients are treated. There are 21 trained nurses and 19 healthcare assistants working on rota shifts on the ward. Each patient bay consists of four to six beds. All the patient bays can be accessed from a connecting corridor that also serves as the circulating area, through which most of the movement in, out and around the ward areas can be made. Please see Appendix 1 for the floor layout of Ward A. 
Ward B is a surgical ward that houses 20 patient beds, and admits and treats patients undergoing breast cancer and urological surgical interventions. It is a symmetrical twin-ward, with two-wings. Each wing houses two nurse stations; one in the middle of the ward, overlooking two large patient bays. The second nurse station is adjacent to a large racetrack design patient bay. While the central location of the nurse station on Ward B mimics the 'Nightingale' layout design (Nightingale, 1860), this ward is a bay ward with racetrack layout type patient bays. For the purpose of this study, only one wing of the ward was selected for the POE, as the two wards are essentially identical. Depending on the patient turnover, between 15 and 20 ward nurses are on rota in Ward B. Please see Appendix 2 for the floor layout of Ward B.

Ward C is a gastroenterology medical ward. It has a racetrack layout with patient bays accessible from a long connecting corridor. There are 32 patient beds and 20 nurses on the ward. As a medical ward, some of the patients are long-term stay, so the patient turnover may be slower compared to the two previous wards which are surgical wards. Unlike Wards A and Ward B, this ward does not have a dedicated nurse station. The architectural space originally designated for ward nurses to serve a nurse station is occupied by a ward clerk who undertakes administrative tasks on behalf of the nurses. Instead of a fixed nurse station, nurses on this ward work from mobile nurse stations, which are computerised lecterns on wheels. Hence, for the purpose of this POE, the ward clerk station was assessed as a nurse station. Please see Appendix 3 for the floor layout of Ward C.

Preparation of Data Collection Instruments: The data collection instrument for this study consists of the interview questions undertaken with the 20 ward nurses (Table 1) and the tailor-prepared WEAT POE checklist. This checklist was used to rate the ADFs of each of the ward elements. The ambient environment parameters such as sound, temperature and lighting levels were measured with the aid of a multi-function Environment Meter (Figure 1).

\section{PLACE TABLE 1 HERE}

Table 1: Extract of Interview Questions

\section{PLACE FIGURE 1 HERE}

\section{FIGURE 1: Photograph of Environment Meter}

For spatial and structural dimensions related to length, width and height, a tape rule was used to obtain such measurements where necessary. Other parameters of the ward elements were obtained by visual observation of the 'presence' or 'absence' of the ADF. An ADF is rated 'not applicable' ( $n / a)$ where it was deemed not relevant to the ward elements being observed. For design features that were unforeseen, but were deemed necessary during the POE, a measurement was taken and recorded in the remarks column 
of the WEAT POE checklist. Such items were followed up and are either explained as part of the evaluation process or discarded if they were eventually deemed irrelevant to the POE.

Data Collection: On the day of the POE, a researcher visited the wards as previously agreed with the ward managers. In all cases the ward manager showed the researcher around the ward and introduced him to the members of staff and briefly explained what the POE was all about. For spaces occupied by patients such as patient bays, the researcher was requested to indicate his intention before accessing such spaces, to ensure patient privacy. It took approximately 6-8 hours to complete the full POE of a ward, consisting of a sample of all the 14 ward elements. The data collection on the three wards presented in this paper was undertaken between 26 January 2016 and 3 February 2016.

As a ward would contain more than one of the 14 ward elements, for the POE, only one of these ward elements was surveyed, which was deemed to be 'representative' of that ward element type on the ward. For example, when surveying patient bays, data was collected on only one patient bay on each ward; and not on all the patient bays. The choice of the patient bay that was surveyed was based essentially on the availability of such spaces at the time the POE walkthrough was undertaken.

To ensure a seamless data collection process, the WEAT POE checklist was prepared in a Microsoft Excel spreadsheet format and made available electronically on a tablet device. The 'presence' (1), 'absence' (0) or 'non-applicability' (n/a), of an ADF was recorded by selecting the right denotation in the appropriate column from a drop-down list in the WEAT POE checklist. This approach reduced the risk of mistype error, as only the items from the drop-down list can be selected. Also, by administering WEAT POE checklist electronically, the risk of error due to data transfer from hard copy to electronic format was virtually eliminated.

WEAT was constructed in seven stages (Figure 2):

Stage 1: Identifying ward elements

Stage 2: Establishing personal constructs

Stage 3: Reviewing assessment tools

Stage 4: Compiling architectural design features

Stage 5: Validating WEAT

Stage 6: Designing an implementation Protocol for WEAT

Stage 7: Testing WEAT

\section{PLACE FIGURE 2 HERE}




\section{Results}

The results of the seven stages are discussed in the following paragraphs.

\section{Stage 1: Identifying Ward Elements}

A total of 14 ward elements were identified from the interviews to constitute those spatial components of a typical hospital ward with which nurses must 'interact' in the course of performing their duties at the case study wards (Figure 3 ). In order to verify that the identified ward elements were complete, a walking interview was conducted with a ward sister who did not participate in the original interviews. A walking interview is undertaken when the researcher and the interviewee together move around a designated spatial environment in order to stimulate interviewee's responses (Evans and Jones, 2011). The list of the previously identified ward elements was shown to the sister, who was asked to confirm that all the ward elements that emerged from the interviews were true and complete as shown. The ward sister confirmed that the compiled list of ward elements was complete. This verification stage reduced the risk of omission and misinterpretation and thus eliminated a 'snowball effect' of errors.

FIGURE 3: Ward Elements coded from NVivo

\section{Stage 2: Establishing Personal Constructs}

A study undertaken earlier by the authors of this paper and published in 2015 , found that the three main personal constructs of nurses affected by the demands of the ward environment are physical, cognitive and sensory (Citation removed for blind peer review). A fourth personal construct termed 'universal' construct, was created, which essentially covers all the areas of universal needs of a nurse interacting with the ward elements, such as privacy, dignity, and comfort. The five environmental assessments tools being reviewed also incorporated these four personal constructs in their evaluation protocol.

\section{Stage 3: Reviewing Assessment Tools}

Five environmental assessment tools were reviewed. (i) Multiphasic Environment Assessment Procedure (MEAP) (Moos and Lemke, 1980). (ii) Professional Environment Assessment Procedure (PEAP) (Lawton et al., 2000). (iii) Therapeutic Environmental Screening Survey for Nursing Homes (TESS-NH) (Sloane et al., 2002). (iv) Sheffield Care Environment Assessment Matrix (SCEAM) (Parker et al., 2004). (v) 
Evaluation of Older People's Living Environments (EVOLVE) (Lewis et al., 2010). The search and selection strategy used to source potential health environment assessment tools for review was to ensure that they focus on the four personal constructs that WEAT should also assess, namely, physical, cognitive, sensory and universal (Table 2).

TABLE 2: Summary of Environmental Assessment Tools Reviewed

\section{Stage 4: Compiling Architectural Design Features}

Stage 4 resulted in the compilation of more than 700 ADFs, which were derived from three main sources. The first source is the result of a thorough review of the five selected built environment assessment instruments used in residential or rehabilitation healthcare facilities (Moos and Lemke, 1980, Lawton et al., 2000, Sloane et al., 2002, Parker et al., 2004, Lewis et al., 2010). The second source was participants' responses to the interview relating to the ADFs they had highlighted to be important for them in their workplace. The third source were architectural design guidebooks pertinent to healthcare facilities design (Neufert and Jones, 1980, Littlefield, 2008); relevant standards and manuals, such as: the 'Health Building Notes' by the UK Department of Health (2014); the 'Inclusive Design Toolkit' by University of Cambridge (2015); and the manual 'Accessibility for the Disabled: A Design Manual for a Barrier Free Environment' by the United Nations (2003).

\section{Stage 5: Validating WEAT}

In the fifth stage the tool was presented to one of the facilities managers at the case study NHS Trust for validation. The goal of the validation process was to reduce subjectivity and add a further level of rigour to WEAT. It is worth noting that the ADFs used in WEAT have been used to measure the four personal constructs in other settings beyond their original use in the five reviewed tools. MEAP was part of environmental assessment protocol undertaken by Cutler et al. (2006), PEAP was used to conduct an independent evaluation was by Schwarz et al. (2004), while Andersson (2011) applied TESS-NH for the remodelling of residential homes. Furthermore, Nordin et al. (2015) tested the adapted version of SCEAM in Sweden, while (Rooney, 2014) used the EVOLVE checklist in comparative analysis of housing for the visually impaired. 


\section{Stage 6: Designing an Implementation Protocol for WEAT}

In stage 6, an implementation protocol of how to use WEAT was designed. Each ward element is allocated a cluster of ADFs in each of the four personal constructs. Each ADF is rated as present (1), or absent (0), or not applicable $(\mathrm{n} / \mathrm{a})$ in the ward element. This rating regime was adapted from Sheffield Care Environment Assessment Matrix, which is one of the five tools that informed the development of WEAT (Parker et al., 2004). The sum of the ratings in each construct represents the adequacy of the ward element to support that particular personal construct. The adequacy measure of a ward element is expressed in the Personal Constructs Impact (PCl) score, which is the aggregate score of the ward element in each of the four constructs, expressed as a percentage of the sum of ADFs used in a POE of that ward element. The higher the $\mathrm{PCl}$ score the better support the ward element is expected to be offering ward nurses. The rating scheme consists of four categories:

Category 1: $75 \%$ and above - Excellent

Category 2: up to $65 \%$ and below $75 \%$ - Good

Category 3: up to $55 \%$ and below $65 \%$ - Adequate

Category 4: Less than $55 \%$ - Suboptimal

For a set of ADFs to have adequately assessed a ward element, at least two-third of the total set of architectural design must have been applied in the POE. If an ADF is rated not applicable (n/a), then that design feature does not form part of the overall calculation of the $\mathrm{PCl}$ score for the particular ward element, as this would skew the overall PCI score of the ward element. In the example shown in Table 3, if the ward element (nurse station) having a set of 12 ADFs in total, out of which six were found to be 'not applicable' (i.e. marked n/a), then such POE would not provide a reliable PCl score, as only $50 \%$ of the original set of ADFs were used. Hence, for the set of ADFs to be fit for purpose, at least eight (making two-third of the original 12) must have been retained and rated as present (1) or absent (0).

TABLE 3: Extract from Ward Environment Assessment Tool 


\section{Stage 7: Testing WEAT}

WEAT was administered on three NHS Trust Hospital wards (Ward A, Ward B and Ward C), the results of which are presented in Table 4. There are two ward elements that obtained a PCl score of more than $75 \%$; namely the nurse stations and the entrances and exits. Conversely, the two ward elements with the lowest $\mathrm{PCl}$ scores are the day room in Ward C (45.61\%) and the storage room in Ward A (51.85\%). The average $\mathrm{PCl}$ scores are also denoted in Table 4. Assuming the threshold of $75 \%$ for excellent performance of a ward element, it can be said that only a few ward elements fulfilled this criterion, such as the three nurse stations; the three entrances and exits and the patient bays in Ward A and Ward C.

TABLE 4: Individual and Average PCI Scores for the Ward Elements of the Three Wards

\section{Limitations}

An environmental assessment tool designed specifically for the evaluation of the ward environment could have benefitted from the possibility of a full-scale validation by testing and retesting the instrument on a large number of hospital wards in order to identify and remove areas that are less fit for purpose, and thus improve its potential to offer an adequate basis for generalisation. WEAT, on the other hand, has only been used and tested on three hospital wards, which opens it to criticism of not being quantitatively validated. As a case study, the researchers' intention was not to attain generalisability. Hence, the depth and breadth of data collected in this study and the triangulation of this provide users of WEAT an initial level of comfort to form the basis of exploring POE further within the healthcare sector.

Another limitation that could be levelled against WEAT is the geographical restriction of the study to a particular NHS Trust. Critics may argue that data collection had focused on a case study in a particular region of the UK, which may not be representative nationwide across all NHS Trusts. However, it is important to note that, while protocols may vary from country to country, the nursing practice and procedures are quite standardised within the National Health Service (Cowan et al., 2005). Therefore, an in-depth exploration of a particular case in a certain geographical location does not confine the knowledge locally constructed to the studied case alone.

Questions could also be raised that WEAT was validated by one person working within the same organisation where the evaluated wards were based, and thus may not be independent. However, while 
this single-person validator may not be deemed an independent person, the validating facilities manager had a thorough knowledge of the facilities and was able to highlight areas of improvements, which were subsequently implemented in the final WEAT checklist.

These limitations also provide opportunities for further research into the POE of healthcare facilities for ward nurses on hospital wards. Further studies may explore the generalisability of WEAT by independently testing it for internal consistency at NHS hospital wards. In addition, there is scope to adapt the parameters of WEAT and test them in non-healthcare buildings in order to advance POE in other settings.

\section{Implications for Nursing Management}

WEAT is a new development that could contribute to the existing body of knowledge in the field of POE of hospital wards. The results of WEAT POE could help to better understand and design nursing tasks, balancing tasks requiring nurses to remain seated over an extended period of time against tasks that require prolonged walking. Nursing tasks such as documentation that have been performed in a sitting position may need to be undertaken while standing at a lectern. This would have ramifications not just for the ward nurses, but also for the facilities managers in terms of space design and requirements or for occupational health advisors when assessing functional capacity with respect to whether a task is performed in a sitting or a standing position.

Human resource managers could use WEAT to provide appropriate context when drawing up a job description. An assessment of the ward environment with the aid of WEAT could provide valuable information on the context where the tasks in the job description would be undertaken. Thereby, a decision could be made on whether adjustments to the job design, the physical workspace (ward element) or even the exemptions of a nurse from certain tasks may be necessary, if this is feasible and in line with the organisation's policy.

Facilities managers may use WEAT to facilitate spatial design and usage in order to ensure the needs of both patients and nursing staff are met in the multifunctional use of space. In addition, WEAT has the potential to inform the redesigning and renovation of existing workspaces similarly to a design checklist. However, these should be carried out against the backdrop that convertible or multipurpose furnishing, 
spatial demarcation, flexible lighting and enhanced noise insulation, may resolve some design problems, instead of a complete and costly renovation, that could temporarily disrupt the care process on the ward.

While POE has existed for more than five decades as part of the building procurement process, one of the most formidable barriers to its widespread use are its ex post characteristics. There is a current problem with architects applying the same techniques repeatedly because of the absence of POE and feedback (Stevenson, 2019). Yet, it is during the occupancy period that the actual performance of a building can be established. It is at this stage that information from existing buildings can be fed forward for future designs (Way and Bordass, 2005). The creation of a national repository, where aggregated information about the performance of existing healthcare facilities could be deposited to inform future designs, would be a meaningful step forward in the promotion of the knowledge base for evidence-based healthcare facilities design through POE (Joseph et al., 2014).

\section{Conclusions}

WEAT is the first comprehensive environmental assessment tool that has the potential to contribute to evidence-based design practices in the healthcare sector. While some authors have argued that the design of the physical workspace can be used to evoke positive outcomes for employees and that a "...functionally uncomfortable workspace draws energy out of the worker that would otherwise be directed to performing work" (Vischer, 2007, p. 180.), this study explored the extent to which such functions have been fulfilled in practice in a hospital ward environment depending on its ADFs. By applying the methodological approach of POE, as a diagnostic tool, WEAT can be used to unpick important ADFs that have the most severe impact on the four personal constructs of ward nurses.

Underpinned by the P-E fit theory, the importance of the relationship between personal constructs of ward nurses and architectural design features of hospital ward environment has been brought to the fore in this research, by exploring the interplay between nurses' personal traits and environmental stimuli in the ward environment. The personal traits in the P-E fit are expressed in terms of the personal constructs of ward nurses, namely, physical, cognitive, sensory and universal. The environmental stimuli are the ADFs of hospital wards where the nurses work. Understanding the parameters of the ADF of the nursing practice environment was essential to ascertain the functional fit between the ward nurse and the ward environment. 
This understanding has been based on an objective evaluation of hospital wards, by analysing in detail the ward elements, where nursing tasks are performed. These 'ward elements' can be found in most hospital wards and ward nurses inevitably interact with them in the course of performing their duties.

In the administration of WEAT, the hospital wards are assessed with respect to their impact on the physical, cognitive, sensory and universal constructs of nurses coming in contact with the ward elements. A comprehensive evaluation of the ward elements, by exploring their impacts on the personal constructs of nurses, will result in a personal construct impact $(\mathrm{PCl})$ score, computed in percentage points, for each of the 14 ward elements. The higher the PCl score of a ward element, the more adequate are its ADFs to support ward nurses in performing the nursing tasks these ward elements are designed to support.

This research comes in a timely period where staff needs start to form a broader discussion in healthcare facilities design as a means to support hospital employees. Yet it is known that undertaking POE of any kind of building, not least healthcare facilities, is still "a scanty endeavour of research-oriented academics, rather than being an embedded practice" (Citation removed for blind peer review) in the building procurement process.

\section{NOTE:}

WEAT is available free for download and use on the correspondence author's website:

For further information on how to use or improve WEAT, please contact: 
References:

ANDERSSON, J. E. 2011. 'Touching up' Communal Space of a Residential Home Setting: A Comparative Study of Tools for Assessing Changes in the Interior Architectural Space. Journal of Housing for the Elderly, 25, 175-216 42p.

ANNANDALE, E., CLARK, J. \& ALLEN, E. 1999. Interprofessional working: an ethnographic case study of emergency health care. Journal of Interprofessional Care, 13, 139-150.

CHOUDHARY, R., BAFNA, S., HEO, Y., HENDRICH, A. \& CHOW, M. 2009. A predictive model for computing the influence of space layouts on nurses' movement in hospital units. Journal of Building Performance Simulation, 3, 171-184.

COWAN, D. T., NORMAN, I. \& COOPAMAH, V. P. 2005. Competence in nursing practice: A controversial concept - A focused review of literature. Nurse Education Today, 25, 355362.

CUTLER, L. J., KANE, R. A., DEGENHOLTZ, H. B., MILLER, M. J. \& GRANT, L. 2006. Assessing and Comparing Physical Environments for Nursing Home Residents: Using New Tools for Greater Research Specificity. The Gerontologist, 46, 42-51.

DEPARTMENT OF HEALTH. 2014. Health building notes [Online]. UK: Department of Health. Available: https://www.gov.uk/government/collections/health-building-notes-coreelements [Accessed 01 March 2019].

DUROSAIYE, I. O., HADJRI, K. \& LIYANAGE, C. L. 2015. Identifying Challenging Job and Environmental Demands of Older Nurses Within the National Health Service. HERD: Health Environments Research \& Design Journal.

DUROSAIYE, I. O., HADJRI, K. \& LIYANAGE, C. L. 2016. Identifying Challenging Job and Environmental Demands of Older Nurses Within the National Health Service. HERD: Health Environments Research \& Design Journal, 9, 82-105.

DUROSAIYE, I. O., HADJRI, K. \& LIYANAGE, C. L. 2019. A critique of post-occupancy evaluation in the UK. Journal of Housing and the Built Environment, 34, 345-352.

DUROSAIYE, I. O., HADJRI, K., LIYANAGE, C. L. \& BENNETT, K. 2017. A matrix for the qualitative evaluation of nursing tasks. Journal of Nursing Management.

EVANS, J. \& JONES, P. 2011. The walking interview: Methodology, mobility and place. Applied Geography, 31, 849-858.

HADJRI, K. \& CROZIER, C. 2009. Post-occupancy evaluation: purpose, benefits and barriers. Facilities.

JANSEN, K. J. \& KRISTOF-BROWN, A. 2006. Toward a multidimensional theory of personenvironment fit. Journal of Managerial issues, 193-212.

JOSEPH, A., QUAN, X., KELLER, A. B., TAYLOR, E., NANDA, U. \& HUA, Y. 2014. Building a knowledge base for evidence-based healthcare facility design through a post-occupancy evaluation toolkit. Intelligent Buildings International, 6, 155-169.

KING, C. 2012. Managing agitated behaviour in older people. Nursing Older People, 24, 33-36.

KRISTOF-BROWN, A. \& GUAY, R. P. 2011. Person-environment fit. In: ZEDECK, S. (ed.) APA handbook of industrial and organizational psychology, Vol 3: Maintaining, expanding, and contracting the organization. Washington, DC US: American Psychological Association.

LAWTON, M. P. 1970. Assessment, Integration, and Environments for Older People. The Gerontologist, 10, 38-46. 
LAWTON, M. P. \& NAHEMOW, L. 1973. Ecology and the aging process. APA website, The psychology of adult development and aging (pp. 619-674).

LAWTON, M. P., NAHEMOW, L. \& TEAFF, J. 1975. Housing Characteristics and the Well-Being of Elderly Tenants in Federally Assisted Housing. Journal Of Gerontology, 30, 601-607.

LAWTON, M. P., WEISMAN, G. D., SLOANE, P., NORRIS-BAKER, C., CALKINS, M. \& ZIMMERMAN, S. I. 2000. Professional environmental assessment procedure for special care units for elders with dementing illness and its relationship to the therapeutic environment screening schedule. Alzheimer Disease \& Associated Disorders, 14, 28-38.

LEWIN, K. 1939. Field Theory and Experiment in Social Psychology: Concepts and Methods. American Journal of Sociology, 44, 868-896.

LEWIS, A., TORRINGTON, J., BARNES, S., DARTON, R., HOLDER, J., MCKEE, K., NETTEN, A. \& ORRELL, A. 2010. EVOLVE: a tool for evaluating the design of older people's housing. Housing, Care and Support, 13, 36-41.

LITTLEFIELD, D. 2008. Metric handbook: planning and design data, Amsterdam London, Architectural.

LU, Y. \& ZIMRING, C. 2012. Can Intensive Care Staff See Their Patients? An Improved Visibility Analysis Methodology. Environment and Behavior, 44, 861-876.

MONROE, R. T., KOMPANEK, A., MELTON, R. \& GARLAN, D. 1997. Architectural styles, design patterns, and objects. IEEE Software, 14, 43-52.

MOOS, R. H. \& LEMKE, S. 1980. Assessing the Physical and Architectural Features of Sheltered Care Settings. Journal of Gerontology, 35, 571-583.

NEUFERT, E. \& JONES, V. 1980. Architects' data, London, Granada.

NIGHTINGALE, F. 1860. Notes on nursing - What it is, and what it is not. AJN The American Journal of Nursing, 47, 508.

NORDIN, S., ELF, M., MCKEE, K. \& WIJK, H. 2015. Assessing the physical environment of older people's residential care facilities: development of the Swedish version of the Sheffield Care Environment Assessment Matrix (S-SCEAM). Bmc Geriatrics, 15, 3-3 1p.

PARKER, C., BARNES, S., MCKEE, K., MORGAN, K., TORRINGTON, J. \& TRENGENZA, P. 2004. Quality of life and building design in residential and nursing homes for older people. Ageing \& Society, 24, 941-962.

PERI BADER, A. 2015. A model for everyday experience of the built environment: the embodied perception of architecture. Journal of Architecture, 20, 244-267.

PREISER, W. F. 2001. The evolution of post-occupancy evaluation: Toward building performance and universal design evaluation. In: STANLEY, L. (ed.) Learning from our buildings: A state-of-the-practice summary of post-occupancy evaluation. United States: National Academy Press.

PROCHORSKAITE, A., COUCH, C., MALYS, N. \& MALIENE, V. 2016. Housing Stakeholder Preferences for the "Soft" Features of Sustainable and Healthy Housing Design in the UK. International Journal Of Environmental Research And Public Health, 13.

ROBSON, C. 1993. Real world research: A resource for social scientists and practitionersresearchers. Blackwell Publishers Ltd., Oxford.

ROONEY, C. 2014. Blind Spot: An Investigation into Lifetime Home Standards and Visual Impairment. PhD Queens Universty Belfast.

ROYAL INSTITUTE OF BRITISH ARCHITECTS. 2013. RIBA PLAN OF WORK [Online]. London, United Kingdom: Royal Institute of British Architects. Available: https://www.architecture.com/knowledge-and-resources/resources-landing-page/ribaplan-of-work\# [Accessed 08 November 2019]. 
SALTHOUSE, T. A. 1990. Working memory as a processing resource in cognitive aging. Developmental Review, 10, 101-124.

SCHWARZ, B., CHAUDHURY, H. \& TOFLE, R. B. 2004. Effect of design interventions on a dementia care setting. American Journal of Alzheimer's Disease and Other Dementias, 19, 172-176.

SLOANE, P. D., MITCHELL, C. M., WEISMAN, G., ZIMMERMAN, S., FOLEY, K. M. L., LYNN, M., CALKINS, M., LAWTON, M. P., TERESI, J., GRANT, L., LINDEMAN, D. \& MONTGOMERY, R. 2002. The Therapeutic Environment Screening Survey for Nursing Homes (TESS-NH): An Observational Instrument for Assessing the Physical Environment of Institutional Settings for Persons With Dementia. The Journals of Gerontology Series B: Psychological Sciences and Social Sciences, 57, S69-S78.

STEVENSON, F. 2019. Housing Fit For Purpose: Performance, Feedback and Learning, Routledge.

TRINKOFF, A. M., LIPSCOMB, J. A., GEIGER-BROWN, J., STORR, C. L. \& BRADY, B. A. 2003. Perceived physical demands and reported musculoskeletal problems in registered nurses. American Journal of Preventive Medicine, 24, 270-275.

UNITED NATIONS 2003. Accessibility for the Disabled: A Design Manual for a Barrier Free Environment. United Nations Economic and Social Commission for Western Asia.

UNIVERSITY OF CAMBRIDGE. 2015. Inclusive Design Toolkit [Online]. United Kingdom: University of Cambridge, Available:

http://www.inclusivedesigntoolkit.com/betterdesign2/whatis/whatis.html [Accessed 01 March 2019].

VAN DER ZWART, J. \& VAN DER VOORDT, T. J. M. 2015. Pre-Occupancy Evaluation of Patient Satisfaction in Hospitals. HERD: Health Environments Research \& Design Journal, 9, 110124.

VISCHER, J. C. 2007. The effects of the physical environment on job performance: towards a theoretical model of workspace stress. Stress and Health, 23, 175-184.

WAY, M. \& BORDASS, B. 2005. Making feedback and post-occupancy evaluation routine 2: soft landings involving design and building teams in improving performance. Building Research \& Information, 33, 353-360.

YIN, R. K. 2009. Case study research: design and methods, 4th ed, Los Angeles, [Calif.] London, SAGE. 
Table 1: Extract of Interview Questions

\begin{tabular}{l}
\hline 1 How long have you worked for the NHS and how long have you been in your current position? \\
$2 \quad \begin{array}{l}\text { Do you consider yourself fit and well? Do you feel fit in your work environment as a ward } \\
\text { nurse? }\end{array}$ \\
$3 \quad$ What type of ward do you work on? \\
How many beds are on the ward? \\
$\begin{array}{l}\text { How would you describe the physical demands of the nursing role on the ward? What support } \\
\text { or help are at a nurse ward disposal in meeting these physical demands? }\end{array}$ \\
$\begin{array}{l}\text { How would you describe the sensory demands of the nursing role on the ward? What support } \\
\text { or help are at a nurse ward disposal in meeting these sensory demands? }\end{array}$ \\
$\begin{array}{l}\text { How would you describe the cognitive demands of the nursing role on the ward? What support } \\
\text { or help are at a nurse ward disposal in meeting these cognitive demands? }\end{array}$ \\
$\begin{array}{l}\text { Do you consider the level of lighting in your ward as adequate? How does the ward lighting } \\
\text { affect your work? }\end{array}$ \\
$\begin{array}{l}\text { Do you consider the heating, ventilation and air-conditioning in your ward as appropriate? How } \\
\text { does the thermal comfort and indoor air quality affect your work? }\end{array}$ \\
$10 \quad \begin{array}{l}\text { How would you describe the noise level in your ward? Does the noise level and/or noise } \\
\text { insulation affect your task performance in any way? If yes, please describe. }\end{array}$ \\
$\begin{array}{l}\text { Please describe the signage system and colour schemes on your healthcare facility. How } \\
\text { adequately do these support your way-finding on the premises? }\end{array}$
\end{tabular}


Table 2: Summary of Environmental Assessment Tools Reviewed

\begin{tabular}{ll}
$\begin{array}{ll}\text { REVIEWED } \\
\text { TOOLS }\end{array}$ & CONSTRUCTS COVERED BY TOOL \\
\hline MEAP1,a & $\begin{array}{l}\text { (i) physical amenities; (ii) social recreational aids; (iii) prosthetic aids; (iv) } \\
\text { orientation aids; (v) safety features; (vi) architectural choice; (vii) space } \\
\text { availability; (viii) staff facilities; and (ix) community accessibility. }\end{array}$ \\
PEAP,b & (i) awareness and orientation; (ii) safety and security; (iii) privacy; (iv) \\
& stimulus regulation; (v) stimulus quality; (vi) functional abilities; (vii) \\
& personal control; (viii) continuity of self; (ix) social contact. \\
TESS-NH & \\
& (i) exit control; (ii) maintenance; (iii) cleanliness; (iv) safety; (v) \\
& orientation/cueing; (vi) privacy; (vii) unit autonomy; (viii) outdoor access; \\
& (ix) lighting; (x) noise; (xi) visual/tactile stimulation; (xii) space seating; \\
& and (xiii) familiarity/home-likeness. \\
& (i) privacy; (ii) personalisation; (iii) choice and control; (iv) community; \\
SCEAM ${ }^{4, d}$ & (v) safety and health; (vi) support for physical frailty; (vii) comfort; (viii) \\
& support for cognitive frailty; (ix) awareness of outside world; (x) \\
& normalness and authenticity; (xi) provision for staff. \\
& (i) personal realisation and choice; (ii) dignity and privacy; (iii) comfort and \\
& control; (iv) personal care; (v) social support inside building; (vi) social \\
& contact outside; (vii) accessibility; (viii) physical support; (ix) sensory \\
& support; (x) dementia support; (xi) health and safety; (xii) security; and \\
& (xiii) working care.
\end{tabular}

CORRELATIONS WITH WEAT CONSTRUCTS

Physical, Cognitive, Universal

Cognitive, Sensory, Universal

Physical, Cognitive, Sensory, Universal

Physical, Cognitive, Universal

Physical, Cognitive, Sensory, Universal (xiii) working care.

\footnotetext{
${ }^{1}$ LAWTON, M. P., WEISMAN, G. D., SLOANE, P., NORRIS-BAKER, C., CALKINS, M. \& ZIMMERMAN, S. I. 2000. Professional environmental assessment procedure for special care units for elders with dementing illness and its relationship to the therapeutic environment screening schedule. Alzheimer Disease \& Associated Disorders, 14, 28-38.
}

2 MOOS, R. H. \& LEMKE, S. 1980. Assessing the Physical and Architectural Features of Sheltered Care Settings. Journal of Gerontology, 35, 571-583.

${ }^{3}$ SLOANE, P. D., MITCHELL, C. M., WEISMAN, G., ZIMMERMAN, S., FOLEY, K. M. L., LYNN, M., CALKINS, M., LAWTON, M. P., TERESI, J., GRANT, L., LINDEMAN, D. \& MONTGOMERY, R. 2002. The Therapeutic Environment Screening Survey for Nursing Homes (TESS-NH): An Observational Instrument for Assessing the Physical Environment of Institutional Settings for Persons With Dementia. The Journals of Gerontology Series B: Psychological Sciences and Social Sciences, 57, S69-S78.

${ }^{4}$ PARKER, C., BARNES, S., MCKEE, K., MORGAN, K., TORRINGTON, J. \& TRENGENZA, P. 2004. Quality of life and building design in residential and nursing homes for older people. Ageing \& Society, 24, 941-962.

${ }^{5}$ LEWIS, A., TORRINGTON, J., BARNES, S., DARTON, R., HOLDER, J., MCKEE, K., NETTEN, A. \& ORRELL, A. 2010. EVOLVE: a tool for evaluating the design of older people's housing. Housing, Care and Support, 13, 36-41.

\footnotetext{
${ }^{a}$ Multiphasic Environment Assessment Procedure

${ }^{b}$ Professional Environment Assessment Procedure

${ }^{\mathrm{c}}$ Therapeutic Environmental Screening Survey for Nursing Homes

${ }^{d}$ Sheffield Care Environment Assessment Matrix

e Evaluation of Older People's Living Environments
} 
TABLE 3: Extract from Ward Environment Assessment Tool

\begin{tabular}{|c|c|c|c|c|c|c|}
\hline \multicolumn{7}{|c|}{ Ward Environment Assessment Tool } \\
\hline $\begin{array}{l}\text { PERSONAL } \\
\text { CONSTRUCTS }\end{array}$ & $\begin{array}{l}\text { WARD } \\
\text { ELEMENT }\end{array}$ & $\begin{array}{l}\text { NUMBER OF } \\
\text { DESIGN } \\
\text { FEATURE }\end{array}$ & $\begin{array}{l}\text { RATING: } \\
\text { Present (1) } \\
\text { Absent (0) } \\
\text { Not Applicable } \\
\text { (n/a) }\end{array}$ & $\begin{array}{l}\text { PCI } \\
\text { SCORE } 1\end{array}$ & DESIGN FEATURE DESCRIPTION & REMARKS \\
\hline sensory & nurse station & 1 & 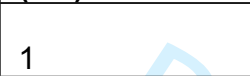 & \multirow{12}{*}{18} & $\begin{array}{l}\text { in case of more than one nurse station, each patient bay visible } \\
\text { from at least one nurse station }\end{array}$ & \\
\hline sensory & nurse station & 2 & 1 & & ambient lighting fitted on desktop & \\
\hline sensory & nurse station & 3 & 1 & & computer keyboard free of glare and reflection & \\
\hline universal & nurse station & 4 & 1 & & staff WC separate from patients' and visitors' facilities & \\
\hline universal & nurse station & 5 & 0 & & staff WC offers gender choices & \\
\hline physical & nurse station & 6 & 1 & & $\begin{array}{l}\text { at least two nursing computer workstations with ergonomic } \\
\text { seating }\end{array}$ & \\
\hline universal & nurse station & 7 & 1 & & $\begin{array}{l}\text { accommodates at least two further nursing staff sitting to facilitate } \\
\text { team collaboration and short meetings }\end{array}$ & \\
\hline physical & nurse station & 8 & 0 & & desktop height adjustable & \\
\hline cognitive & nurse station & 9 & 0 & & tabard pinafore provided for medication rounds & \\
\hline cognitive & nurse station & 10 & 1 & & $\begin{array}{l}\text { equipped with adequate stationeries and writing materials for note } \\
\text { taking }\end{array}$ & \\
\hline cognitive & nurse station & 11 & 1 & & $\begin{array}{l}\text { room numbers placed on door frames or adjacent walls and not } \\
\text { on doors themselves to be visible even when the door is open }\end{array}$ & \\
\hline universal & nurse station & 12 & 1 & & air quality satisfactory (not stuffy or draughty) & \\
\hline & & Total & 9 & $75 \%$ & & \\
\hline
\end{tabular}

${ }^{1}$ PCI Score: Personal Construct Impact Score 


\begin{tabular}{|l|r|r|r|r|}
\hline \multicolumn{5}{|c|}{ PCI Scores of the Case Study Hospital Wards } \\
\hline Ward Elements & \multicolumn{1}{|l|}{ Ward A } & \multicolumn{1}{l|}{ Ward C } & \multicolumn{1}{l|}{ Average PCI } \\
\hline Nurse station & $79.41 \%$ & $78.46 \%$ & $77.27 \%$ & $78.38 \%$ \\
\hline Patient bay & $78.05 \%$ & $72.15 \%$ & $78.21 \%$ & $76.14 \%$ \\
\hline Side room & $72.62 \%$ & $63.51 \%$ & $67.86 \%$ & $68.00 \%$ \\
\hline Staff room & $66.67 \%$ & $74.36 \%$ & $71.79 \%$ & $70.94 \%$ \\
\hline Ward manager's office & $71.43 \%$ & $77.78 \%$ & $71.43 \%$ & $73.54 \%$ \\
\hline Doctor's office & $72.73 \%$ & $82.35 \%$ & $74.19 \%$ & $76.42 \%$ \\
\hline Day room & $70.18 \%$ & $67.86 \%$ & $45.61 \%$ & $61.22 \%$ \\
\hline Corridor & $61.82 \%$ & $60.78 \%$ & $67.27 \%$ & $63.29 \%$ \\
\hline Storage room & $51.85 \%$ & $60.00 \%$ & $60.00 \%$ & $57.28 \%$ \\
\hline Clean utility & $63.64 \%$ & $65.12 \%$ & $64.44 \%$ & $64.40 \%$ \\
\hline Sluice & $73.68 \%$ & $85.71 \%$ & $71.43 \%$ & $76.94 \%$ \\
\hline Bathroom \& WC & $74.58 \%$ & $78.95 \%$ & $66.07 \%$ & $73.20 \%$ \\
\hline Kitchen & $56.25 \%$ & $75.76 \%$ & $82.86 \%$ & $71.62 \%$ \\
\hline Entrances \& Exits & $85.00 \%$ & $85.71 \%$ & $82.61 \%$ & $84.44 \%$ \\
\hline
\end{tabular}




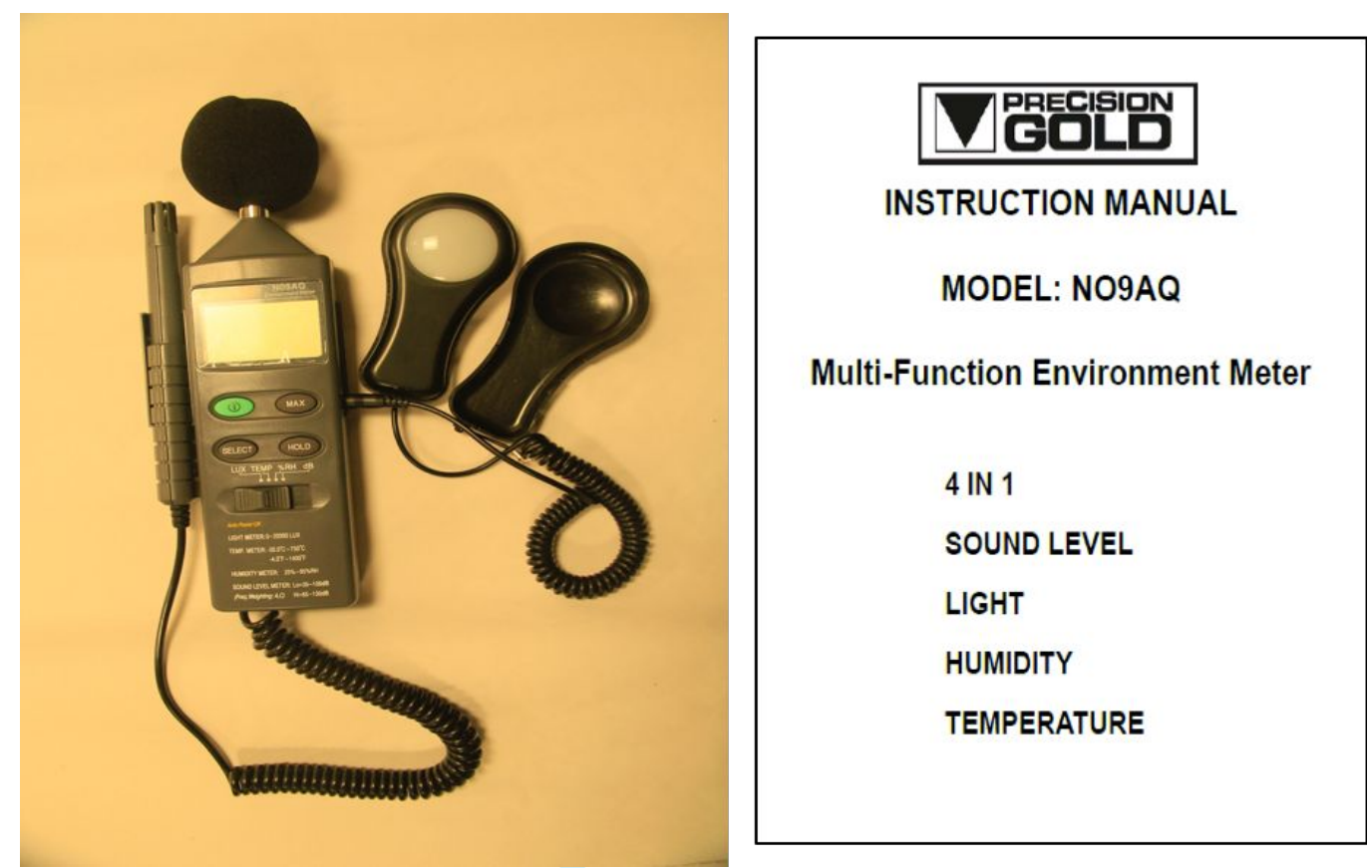

Figure 1: Photograph of Environment Meter 


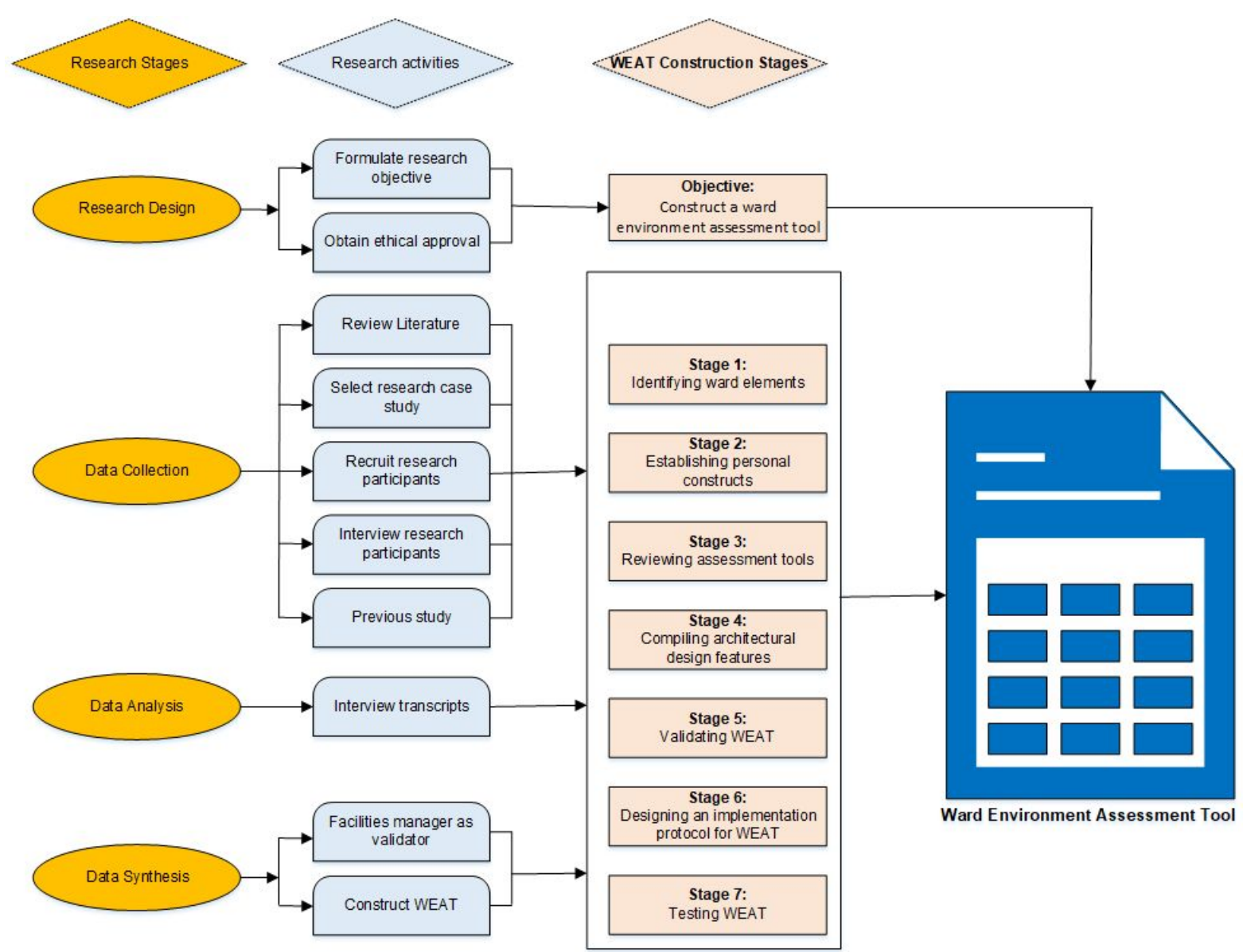

Figure 2: A Flowchart of the Construction of WEAT 


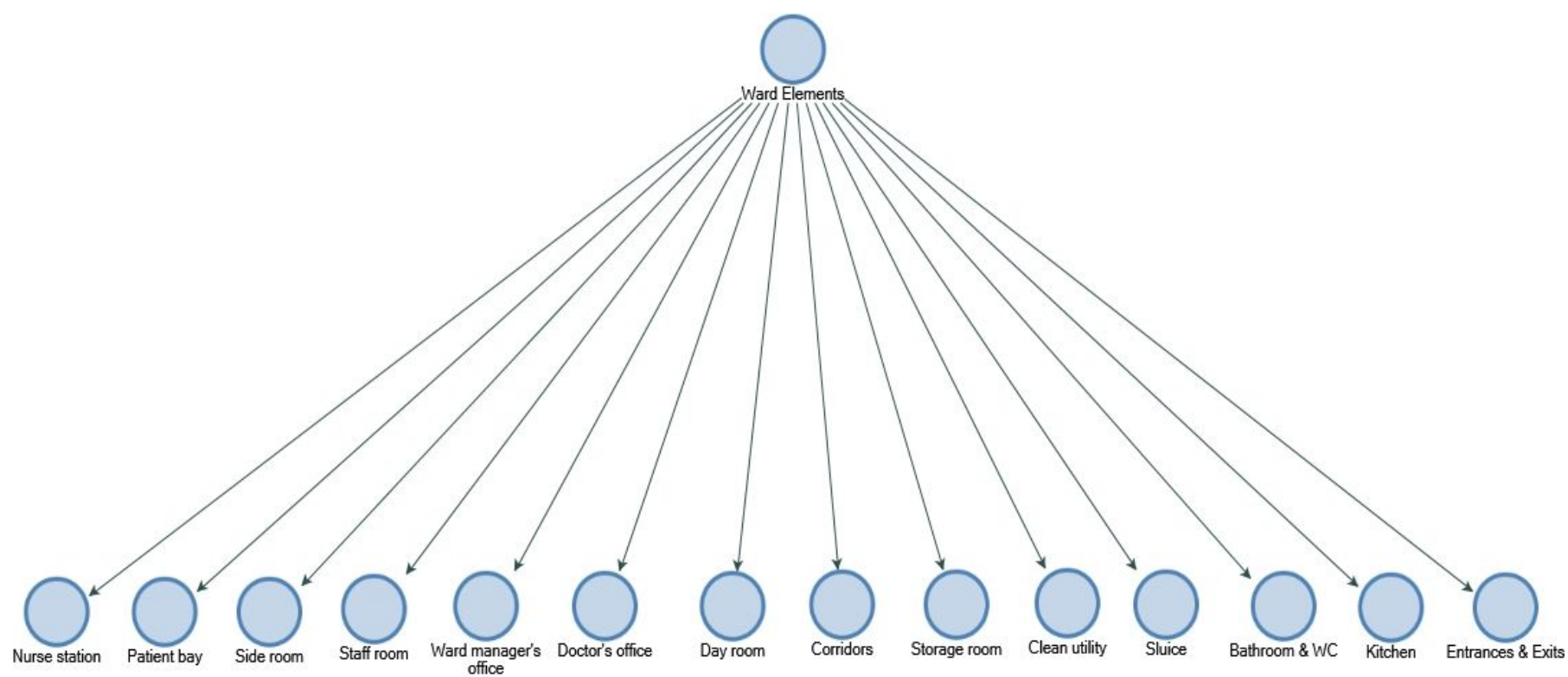

Figure 3: Ward Elements coded from NVivo 11 for Windows ${ }^{1}$

\section{${ }^{1}$ Description of ward elements}

Nurse station: Reception and administrative desk for ward nurses

Patient bay: Multi-occupancy patient room

Side room: Single-occupancy patient room for infection control

Staff room: Changing and eating room for staff

Ward manager's office: An office space for the ward manager

Doctor's office: An office space for the duty doctor

Day room: Meeting room for patients and families

Corridors: Circulating and connecting areas

Storage room: Room for consumables and small medical equipment

Clean utility: Medicines storage and for preparation of medication

Sluice: Room for dirty linens and for storage of clinical wastes before disposal

Bathroom \& WC: Wet rooms, bathrooms, showers and toilets

Kitchen: Room for the storage and preparation of meals for staff

Entrances \& Exits: Access points to ward 